\title{
A clinical study on single-visit root canal retreatments on consecutive 173 patients: frequency of periapical complications and clinical success rate
}

\author{
Eyuboglu, Tan Firat ; Olcay, Kezban ; Özcan, Mutlu
}

\begin{abstract}
OBJECTIVES This study assessed the outcome measures of single-visit root canal retreatments and frequency of periapical complications considering preoperative, intraoperative and postoperative factors. MATERIALS AND METHODS Between November 2011 and December 2012, in 173 patients, a total of 234 endodontically treated teeth were retreated in a single appointment by one experienced endodontist. Five teeth were extracted and 119 teeth were lost to follow-up yielding to 110 teeth (47\%) to be examined by two calibrated examiners for the outcome of healing (periapical index score-PAI $\leq 2$; no signs or symptoms) or non-healing (presence of apical periodontitis-PAI $>2$; signs or symptoms). Preoperative, intraoperative and postoperative factors were evaluated for their association with the outcome. Data were analysed using Fisher's exact and Fisher-Freeman Halton tests for bivariate analysis to identify potential outcome predictors. Logistic regression models were used for multivariate analysis to determine significant outcome predictors. RESULTS Mean observation time was 29 months. Follow-up assessment revealed 100 teeth $(90.9 \%)$ as healed and 10 teeth $(9.1 \%)$ non-healed. Age, gender, tooth type and preoperative (pain, periodontal defects, root filling density and length), intraoperative (sealer extrusion) and postoperative (type of coronal restorations) factors did not significantly affect the outcome $(\mathrm{p}>0.05)$. Preoperative periradicular lesions with diameters less than $5 \mathrm{~mm}$ presented significantly better outcome than larger lesions ( $\mathrm{p}<0.05$; odds ratio (OD) 6; $95 \%$ CI 1.45-24.85). Logistic regression model showed an increased risk of non-healing for the parameter of preoperative periradicular lesions with diameters larger than $5 \mathrm{~mm}$ (OD 6.42; $95 \%$ CI 1.51-27.27). CONCLUSIONS Single-appointment root canal retreatments presented a favourable success rate. Only preoperative lesion size had a significant effect on the outcome where the lesions smaller than 5 $\mathrm{mm}$ performed significantly better healing. CLINICAL RELEVANCE Single-appointment root canal retreatments could be considered as a viable treatment option for orthograde retreatment cases with periradicular lesion size smaller than $5 \mathrm{~mm}$.
\end{abstract}

DOI: https://doi.org/10.1007/s00784-016-1957-2

Posted at the Zurich Open Repository and Archive, University of Zurich

ZORA URL: https://doi.org/10.5167/uzh-146168

Journal Article

Accepted Version

Originally published at:

Eyuboglu, Tan Firat; Olcay, Kezban; Özcan, Mutlu (2017). A clinical study on single-visit root canal retreatments on consecutive 173 patients: frequency of periapical complications and clinical success rate. Clinical Oral Investigations, 21(5):1761-1768.

DOI: https://doi.org/10.1007/s00784-016-1957-2 


\section{A clinical study on single-visit root canal retreatments on consecutive 173 patients: \\ Frequency of periapical complications and clinical success rate}

\section{Tan Firat Eyuboglu $\bullet$ Kezban Olcay ${ }^{2} \bullet$ Mutlu Özcan $^{3}$}

${ }^{1}$ T.F. Eyuboglu

Istanbul Medipol University, School of Dentistry, Department of Endodontics, Istanbul, Turkey e-mail: tfeyuboglu@yahoo.com

${ }^{2}$ K. Olcay

Istanbul Medipol University, School of Dentistry, Department of Endodontics, Istanbul, Turkey

${ }^{3} \mathrm{M}$. Özcan

University of Zürich, Dental Materials Unit, Center for Dental and Oral Medicine, Clinic for Fixed and Removable Prosthodontics and Dental Materials Science, Plattenstrasse 11, $\mathrm{CH}-8032$, Zürich, Switzerland

Short title: single-visit root canal retreatments

\section{Correspondance to:}

Assistant Prof. Tan Fırat Eyüboğlu

Istanbul Medipol Üniversity

School of Dentistry

Department of Endodontics

Atatürk Bulvarı No:27

Unkapanı, Fatih 34083

İstanbul, Turkey

Tel: +90-212-453-48-48

Fax:+90-212-521-04-26

e-mail: tfeyuboglu@yahoo.com 


\section{Abstract}

Objectives: This study assessed the outcome measures of single-visit root canal retreatments, frequency of periapical complications considering preoperative, intraoperative and postoperative factors.

Materials and Methods: Between November 2011 and December 2012, in 173 patients a total of 234 endodontically treated teeth were retreated in a single appointment by one experienced endodontist. Five teeth were extracted and 119 teeth were lost to follow-up yielding to 110 teeth $(47 \%)$ to be examined by two calibrated examiners for the outcome of healing (periapical index score-PAI $\leq 2$; no signs or symptoms) or non-healing (presence of apical periodontitis-PAl>2; signs or symptoms). Preoperative, intra-operative and postoperative factors were evaluated for their association with the outcome. Data were analyzed using Fisher's Exact and FisherFreeman Halton tests for bivariate analysis to identify potential outcome predictors. Logistic regression models were used for multivariate analysis to determine significant outcome predictors.

Results: Mean observation time was 29 months. Follow-up assessment revealed 100 teeth $(90.9 \%)$ as healed and 10 teeth $(9.1 \%)$ non-healed. Age, gender, tooth type, preoperative (pain, periodontal defects, root filling density and length), intraoperative (sealer extrusion) and postoperative (type of coronal restorations) factors did not significantly affect the outcome $(p>0.05)$. Preoperative periradicular lesions with diameters less than $5 \mathrm{~mm}$ presented significantly better outcome than larger lesions ( $p<0.05$; Odds ratio (OD):6; $95 \% \mathrm{Cl}: 1.45-24.85$ ). Logistic regression model showed an increased risk of non-healing for the parameter of preoperative periradicular lesions with diameters larger than $5 \mathrm{~mm}$ (OD:6.42; 95\% Cl:1.5127.27). 
Conclusions: Single appointment root canal retreatments presented favourable success rate. Only preoperative lesion size had a significant effect on the outcome where the lesions smaller than $5 \mathrm{~mm}$ performed significantly better healing.

Clinical Relevance: Single appointment root canal retreatments could be considered as a viable treatment option for orthograde retreatment cases with periradicular lesion size smaller than 5 $\mathrm{mm}$.

Keywords: PAl scores $\bullet$ Periapical complications $\bullet$ Periapical lesion $\bullet$ Root canal retreatment $\bullet$ Single appointment endodontic therapy 


\section{Introduction}

The primary goal of endodontic treatment is to prevent or heal apical periodontitis (AP) [18] but it has been reported in cross-sectional studies from different countries that more than $30 \%$ of all endodontically treated teeth in the studied populations are associated with AP, or "post treatment disease" $[3,6,11]$.

Post treatment diseases could be treated by two options including orthograde retreatment and apical surgery [11]. In a previous study, orthograde retreatments presented success rate of $81 \%$ classified as "healed" and $93 \%$ as "no symptoms and fully functional" [8]. In a systematic review, it has also been concluded that endodontic surgery offers more favourable initial success but orthograde retreatment yields to a better long-term outcome [28]. Although early results of single visit treatments are contradictory [12,30,31], due to novel techniques and equipment available today [34] and patient requests, a considerable amount of increased interest and effort were accumulated on single visit treatments. Completing the treatment in a single appointment reduces the treatment time and cost, decreases microleakage risk and avoiding recontamination of root canals between appointments in multiple visit treatments $[9,33,35]$. In fact, no significant differences were observed in healing of periapical radiolucency between teeth treated in one visit (without) and those treated in two visits usibg calcium hydroxide for 4 weeks and that the presence of a positive bacterial culture at the time of filling did not influence the outcome of treatment [19]. Similarly, Ashraf et al. reported single appointment retreatments with a success rate of $84.9 \%$ and recommended single appointment retreatments for symptom-less teeth [1]. 
Due to excessive request from patients as a result of limited time for dental visits during working hours and long travelling time required to visit dental offices, single appointment treatments $[9,19,33]$ and retreatments [1] for root canal treatments could bring economical advantages.

The objective of this study therefore was to assess the frequency of periapical complications and success rate of single appointment non-surgical root canal retreatments retrospectively considering preoperative, intraoperative and postoperative factors.

\section{Materials and methods}

\section{Inclusion and exclusion criteria}

This retrospective study included patients who were in need of orthograde retreatment and treated in a single appointment accordingly at Istanbul Medipol University between November 2011 and December 2012. The ethics committee of the same university approved the study and all enrolled subjects signed a written informed consent. All retreatments were assigned due to persisting periapical lesions, preoperative signs and symptoms, coronal and/or apical leakage of root canals. In total, in 173 patients, 234 teeth were retreated by one endodontist (T.F.E) who had an experience of 12 years. The diagnoses of the relevant teeth were made with a panoramic (KODAK 9000, Carestream Health, Rochester, New York, USA) and periapical radiograph (KODAK RVG 5100, Carestream Health) using parallel technique with an exposure time of $0.16 \mathrm{~s}$ and exposure dose of1.22 mGy. The teeth diagnosed with excessive periodontal disease, vertical root fractures or those that received surgical endodontic treatment were excluded.

\section{Retreatment procedure}

The treatments were carried out in single appointment. All restorations (single crowns and fixed dental prosthesis) were removed initially to gain direct access to the relevant tooth. Roots posts 
were primarily removed using an ultrasonic device (UDS-N2, Woodpecker, Guangxi, PRC) and if required with a portegue.

After having access to the previously obturated root canals, \#1, \#2 ve \#3 Gates Glidden (GG) burs (Mani Inc, Tochigi, Japan) and \#15 Kerr files (Mani Inc) were used to remove the root canal filling completely. No chemical solvent was used to remove the gutta-percha or the sealer. Cleaning and shaping of the canal were performed employing a crown-down technique using nickel-titanium rotary instruments (Revo-S Micro-Méga, Besançon, France). After measuring the root lengths with apex locater (Apex Pointer, Micro-Méga), each tooth was prepared up to AS 40 file, $0.5 \mathrm{~mm}$ short of the apex. The canals were irrigated after the use of each instrument with $1 \mathrm{ml}$ of $2.5 \%$ sodium hypochlorite $(\mathrm{NaOCl})$. The last irrigation was accomplished using $2.5 \mathrm{ml} 5 \%$ ethylene diamine tetra-acetic acid (EDTA), $2.5 \mathrm{ml}$ of $2.5 \% \mathrm{NaOCl}, 5 \mathrm{ml}$ of distilled water, respectively. Single-cone technique was then used to fill the root canals with either AS35 or AS40 gutta-percha cones (Revo-S, Micro-Méga). Root canal filling paste (AH Plus, Dentsply, DeTrey, Konstanz, Germany) was introduced into the root canal using master cones with a brushing motion and accessory gutta-percha cones (SU 25, Revo-s, Micro-Méga) were used when needed using non-compaction method.

A tota-etch bond (Single bond 2, 3M ESPE, St. Paul, MN, USA) technique was used according to manufacturer's instructions prior to coronal restoration. Flowable resin composite (Filtek Ultimate Flowable, 3M ESPE, St. Paul, MN, USA) was used as base material in order to seal the canal orifices. Thereafter, the coronal restoration was made with resin composite (Filtek Ultimate, 3M ESPE) or a fiber post (Cytec Blanco, HT-Glasfiber, E. Hahnenkratt GmbH, Königsbach-Stein, Germany) and composite core (RelyX U200, 3M ESPE) prior to a fixed prosthetic restoration depending on the prosthetic plan. 


\section{Radiographic evaluation}

A periapical radiograph of the relevant tooth was made immediately after the retreatment with paralleling technique using the same digital radiograph with the same parameters used prior to treatment as described above. The preoperative and intraoperative data were recorded at the database.

\section{Follow-up evaluation}

During the follow-up, clinical signs and symptoms of the relevant tooth were recorded and radiographs were made to record periapical indices (PAI). The principal investigator (T.F.E.) and the coexaminer (K.O) examined all preoperative and postoperative radiographs. The PAI scores of periapical healing and non-healing were recorded for each endodontically retreated tooth during the follow up after the retreatment.

The endodontically retreated teeth were clinically examined and patient response was recorded upon pain in percussion, palpation and chewing (present or absent), any swelling, fistula or sign of infection at the gingival tissue (present or absent), quality of the coronal restoration, occlusal marginal defects (present or absent) and the quality of the root canal filling (length and density of the root filling) (Table 1).

\section{Calibration of the observers}

All PAI scores were obtained from periapical radiographs with a paralleling technique. Two investigators were calibrated for recording PAI with a calibration kit of 100 reference radiographs [12]. The PAl scores were dichotomized to reflect absence (PAI $\leq 2)$ or presence (PAI>2) of apical periodontitis. Teeth with multiple root canals were scored for the root canal with the highest PAI score.

\section{Statistical analysis}


Data obtained from preoperative, intra-operative and postoperative factors and their association with the outcome were statistically analysed using a software programme (Number Cruncher Statistical System, NCSS 2007 and Power Analysis and Sample Size, PASS 2008 Statistical Software, Utah, USA). Fisher's Exact and Fisher-Freeman Halton tests were used for bivariate analysis to identify potential outcome predictors and logistic regression models were used for multivariate analysis to assess significant outcome predictors. Inter-examiner and intraexaminer Cohen`s Kappa scores were calculated twice within two months interval. Post hoc power analyses was made for the parameters studied.

\section{Results}

Post hoc power analyses indicated preoperative PAI score, preoperative radioluceny less than

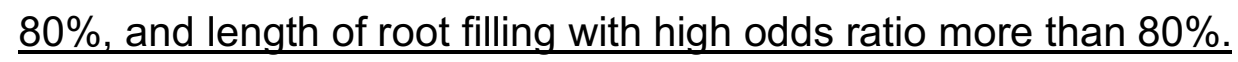

Of all patients treated ( $\mathrm{N}=234$ teeth), $119(50.8 \%)$ teeth, 98 of 173 patients $(56.6 \%)$ were lost until final follow-up, 5 teeth were extracted of which 4 were for restorative and 1 for periodontal reasons. Out of 98 patients (119 teeth), 1 patient was deceased (1 tooth), 28 patients declined recalls (34 teeth), 69 patients did not respond (84 teeth). Out of 110 teeth (47\%) were examined by two calibrated examiners for the following outcomes: "healed" (periapical index score: PAI $\leq 2$; no signs or symptoms) or "non-healed" (presence of apical periodontitis: PAI>2, signs or symptoms) (Table 1). Inter-examiner and intra-examiner Kappa scores ranged between 0.936 and 0.964 showing a very good agreement (Table 2). There was statistically no significant difference among the factors between inception cohort and study group ( $p>0.05)$ (Table 1).

Until the final follow up, 100 teeth (90.9\%) were categorized as "healed" and 10 teeth $(9.1 \%)$ as "non-healed". The mean age of the study group was $43.5 \pm 14.4$. While $45(60.8 \%)$ of the patients 
were female, $29(39.2 \%)$ of them were male. The mean age of the "healed" group was $43 \pm 13.7$ whilst the "non-healed" group was $38 \pm 15.2$ with no significant difference $(p=0.745 ; p>0.05)$. Tooth type or tooth location also had no significant effect on the outcome. Among all 10 "non-healed" teeth that had PAI scores $>2$ ( 6 teeth $P A I=3,3$ teeth $P A I=4,1$ tooth $P A I=5)$, only 1 was clinically symptomatic $(\mathrm{PAl}=4)$. One of them had a persistent and growing lesion at the bifurcation area diagnosed with a strip perforation and extracted during the follow-up $(P A I=3)$. Six teeth presented smaller lesions compared to baseline situation, including the symptomatic tooth and the perforated tooth), lesions did not change in 3 teeth and became larger in 1 tooth.

There was no correlation between preoperative pain and outcome measures of the study $(p>0.05)$ (Table 3). Preoperative PAl scores had a significant effect on the outcome $(p=0.014)$. Preoperative peri-radicular lesion with a diameter smaller than $5 \mathrm{~mm}$ demonstrated significantly better outcome than the larger lesions ( $p=0.025$; Odds ratio (OD): $6 ; 95 \% \mathrm{Cl}: 1.45-24.85)$ (Table 3). Preoperative PAI score 5 had a significantly increased failure ratio (OD: $6.8 ; 95 \% \mathrm{Cl}$ : $1.75-$ 26.73) (Table 3).

Preoperative periodontal defects, preoperative root filling material, density and length, intraoperative root filling length, root filling voids, sealer extrusion, postoperative quality, type of coronal restorations and post applications had no significant effect on the outcome $(p>0.05)$. Although the length of root filling had no effect on the outcome, OD for adequate root canal filling length was calculated to be $3.13(95 \% \mathrm{Cl}$ : 0.51-19.35) with a greater difference compared to other root canal filling lengths according to the logistic regression models (Table 4). 


\section{Discussion}

With the increased success rate and newly developed materials, single appointment root canal treatment procedure has become a viable treatment protocol for both primary root canal treatments and retreatments $[1,9,19,33,34]$. Yet, preoperative factors affecting the treatment outcome are essential for decision making in endodontic treatment $[5,6,8,11]$. This study solely focused on the outcomes of single visit retreatment considering possible preoperative, intraoperative and postoperative factors affecting the results.

This retrospective study presented $90.9 \%$ success rate as $98.2 \%$ of the teeth were asymptomatic and fully functional after a mean observation time of 29 months. Age, gender, tooth type and periodontal defects had no effect on the outcome measures similar to other studies $[5,8]$. All patients with asymptomatic non-healed teeth were informed about the situation. It is critical to communicate with the patients for retaining their teeth whether with successful outcome or being asymptomatic with a notification of routine follow-ups of the involved teeth. Patients in this group and those in the study group were all in agreement for retaining their teeth and were willing to attend further follow-ups.

Root canal retreatment without apical periodontitis was reported to have a high healing rate $(93-98 \%)$ in previous studies $[5,8,23,24]$ but due to high incidence of lesions in the teeth involved in the study group, only one tooth was free of apical periodontitis. Therefore, in this study, no conclusions could be drawn regarding the success rate of retreatments in apical periodontitis free teeth. Yet, the presence of apical periodontitis in this study, is an indispensible factor for the success rate of both root canal treatments and retreatments which was frequentyl reported in previous studies with a success rate in range of $64-87 \%[7,8,10,16,17,24,26]$. Contrary to previous studies, the presence of apical periodontitis with a reasoning of stronger predictive ability of other 
prognostic factors (presence of perforation, root filling quality, postoperative restoration) that were unique to retreatment [8], in this study, none of the prognostic factors that were reported to be primary predictors, statistically affected the results. The size of the apical periodontitis was critical for the outcome of retreatments that was consistent with other studies [4,26]. Both in primary root canal treatments [17] and root canal retreatments [16], the size of the lesion has not been reported to be a significant predictor, providing that larger lesions need longer observation time. Considering the observation time of this study, the impact of lesion size on the outcome may decrease over time, which needs to be verified in long-term follow up.

Preoperative perforation and root filling quality were previously reported to be primary predictors [8] but in this study, no evidence was found supporting this statement. The reason for this might be the study group involved in this study that consisted of patients who applied to the university clinics for compromised root canal treatments they had received previously that were poorly done as a consequence of insufficient instrumentation, root canal filling or compromised coronal restoration. Therefore, the number of preoperative perforation cases in the archives was scarce and none were good enough for the indication of orthograde retreatment. Only one postoperative perforation case could not be treated and therefore extracted suggesting a deleterious effect of perforation on the outcomes of orthograde retreatments.

The quality of previous root filling (root filling length and density) has been reported to be the most important outcome predictor $[5,8]$. The teeth with adequate previous root canal filling might be more resistant to orthograde retreatment $[26,27]$ due to possible extraradicular biofilm $[22,25,29]$, apical cysts $[15,21]$, foreign-body reactions $[13,14]$ or undiagnosed root cracks. On the other hand, teeth with inadequate previous root canal filling are more susceptible to routine orthograde retreatment $[2,27]$. Although adequate root canal filling length showed an OD of 3.13 
(95\% Cl: 0.51-19.35), no statistically significance was found between the quality of previous root canal filling and outcome of retreatments. This might be due to the approach of the previous dentist to root canal treatment causing many failed or failing cases to be involved of insufficiently shaped and filled root canals with only one or two .02 taper gutta-percha cones, ending around the middle third of the root canal. Hence, this could have affected any statistical difference consisting adequate previous root canal treatment cases.

The archive consisted of patients with inadequate previous root canal treatments in terms of both root canal filling length and density. There were only 9 teeth with adequate length that lacked the ideal density, whilst only 2 teeth had adequate density, yet both were overfilled. Although apical lesion size seemed to be the only predictor according to the results of this study, prolonged follow-up time and increased number of patients in the study group may reveal other predictors regarding the outcome and success rate of single appointment orthograde root canal treatment.

Endodontic treatment requires multi-step procedures including root canal disinfection and a final functioning, aesthetic coronal restoration. The importance of coronal restorations was reported in previous studies as primary predictors regarding the outcome of endodontic treatments $[17,20,32]$. Since all treatments were carried out in single appointment, the negative effect of temporary restorations was not an issue in this study [8]. The type of the definitive restoration was also found to be ineffective on the outcome of orthograde retreatments that was also in agreement with previous studies $[5,8]$. The single appointment approach might also be the reason for high success rate of orthograde retreatments in this study regarding the previous studies $[1,5,8,9,19,33,35]$. Patients are being followed up for long-term observations on the outcome measures reported in this study. 


\section{Conclusions}

After 29 months of mean observation time, of the single appointment orthograde retreatments of 110 endodontically treated teeth, $90.9 \%$ of the teeth were healed, whereas $98.2 \%$ remained asymptomatic and functional. The primary and only predictor seems to be the size of apical periodontitis $(>5 \mathrm{~mm})$.

\section{Conflict of Interest}

The authors declare that they have no conflict of interest. 


\section{References}

1. Ashraf H, Milani AS, Shakeri Asadi S (2007) Evaluation of the success rate of nonsurgical single visit retreatment. Iranian Endod J 2(x):69-72

2. Bergenholtz G, Lekholm U, Milthon R, Heden G, Odesjö B, Engstrom B (1979) Retreatment of endodontic fillings. Scand J Dent Res 87(x):217-224

3. Boucher Y, MatossianL, Rilliard F, Machtou P (2002) Radiographic evaluation of the prevalence and technical quality of root canal treatment in a French subpopulation. International Endodontic Journal 35;229-238

4. Chugal NM, Clive JM, Spangberg LSW (2001) A prognostic model for assessment of the outcome of endodontic treatment: Effect of biologic and diagnostic variables. Oral Surg Oral Med Oral Pathol Oral Radiol Endod 91, 342-352

5. de Chevigny C, Dao TT, Basrani BR, Marquis V, Farzaneh M, Abitbol S, Friedman S (2008) Treatment outcome in endodontics: the Toronto study-phases 3 and 4: orthograde retreatment. J Endod 34;131-137

6. Dugas NN, Lawrence HP, Teplitsky PE, Pharoah MJ, Friedman S (2003) Periapical health and treatment quality assessment of root-filled teeth in two Canadian populations. Int Endod J $36: 181-192$

7. Farzaneh M, Abitbol S, Lawrence HP, Friedman S (2003) Treatment outcome in endodontics: the Toronto Study. Phase II: initial treatment. J Endod 29:787-793

8. Farzaneh M1, Abitbol S, Friedman S (2004) Treatment outcome in endodontics: the Toronto study. Phases I and II: Orthograde retreatment. J Endod 30:627-633

9. Field JW, Gutmann JL, Solomon ES (2004) A clinical and radiographic retrospective assessment of the success rate of single visit root canal treatment. Int Endod J 37:70-82 
10. Friedman S, Abitbol S, Lawrence HP (2003) Treatment outcome in endodontics: The Toronto Study. Phase 1: initial treatment. J Endod 29:787-793

11. Friedman S (2002) Considerations and concepts of case selection in the management of post-treatment endodontic disease (treatment failures). Endod Topics 1:54-78

12. Jurkak JJ, Bellizzi R, Loushine RJ (1993) Successful single visit endodontics during operation desert shield. J EndoD 19:412-413

13. Nair PN, Sjögren U, Krey G, Sundqvist G (1990) Therapy-resistant foreign body giant cell granuloma at the periapex of a root-filled human tooth. J Endod 16:589-595

14. Nair PNR (2003) Non-microbial etiology: Foreign body reaction maintaining post-treatment apical periodontitis. Endod Topics 6:114-134

15. Nair PNR (2003) Non-microbial etiology: Periapical cyst sustains post-treatment apical periodontitis. Endod Topics 6:96-113

16. Ng YL, Mann V, Gulabivala K (2008) Outcome of secondary root canal treatment: a systematic review of the literature. Int Endod J 41:1026-1046

17. Ng YL, Mann V, Rahbaran S, Lewsey J, Gulabivala K (2008) Outcome of primary root canal treatment: systematic review of the literature -- Part 2. Influence of clinical factors. Int Endod J 41:6-31

18. Ørstavik D, Pitt Ford TR (1998) Apical periodontitis: microbial infection and host responses. In: Ørstavik D, Pitt Ford TR, eds. Essential endodontology: prevention and treatment of apical periodontitis. Oxford: Blackwell Science, 1-8

19. Peters LB, Wesselink PR (2002) Periapical healing of endodontically treated teeth in one and two visits obturated in the presence or absence of detectable microorganisms. Int Endod $\mathrm{J}$ $35: 660-667$ 
20. Ray HA, Trope M (1995) Periapical status of endodontically treated teeth in relation to the technical quality of the root filling and the coronal restoration. Int Endod J 28:12-18

21. Simon JH (1980) Incidence of periapical cysts in relation to the root canal. J Endod 6:845848

22. Siqueira JF Jr (2003) Periapical actinomycosis and infection with Propionibacterium propionicum. Endod Topics 6:78-95

23. Sjögren U, Hagglund B, Sundqvist G, Wing K (1990) Factors affecting the long-term results of endodontic treatment. J Endodont 16:498-504

24. Strindberg LZ (1956) The dependence of the results of pulp therapy on certainfactors: anan alytic study based onradiographic and clinical follow-up examination. Acta Odontol Scand 14:xX$x x$

25. Sunde PT, Olsenl, Debelian GJ, Tronstad L (2002) Microbiota of periapical lesions refractory to endodontic therapy. J Endodont 28:304-310

26. Sundqvist G, Figdor D, Persson S, Sjögren U (1998) Microbiologic analysis of teeth with failed endodontic treatment and the outcome of conservative re-treatment. Oral Surg Oral Med Oral Pathol Oral Radiol Endod 85:86-93

27. Sundqvist G, Figdor D (2003) Life as an endodontic pathogen: ecological differences between the untreated and root-filled root canals. Endod Topics 6:3-28.

28. Torabinejad M, Corr R, Handysides R, Shabahang S (2009) Outcomes of nonsurgical retreatment and endodontic surgery: a systematic review. J Endodont 35:930-937

29. Tronstad L, Sunde PT (2003) The evolving new understanding of endodontic infections. Endod Topics 6:55-77 
30. Trope M, Delano EO, Orstavik D (1999) Endodontic treatment of teeth with apical periodontitis: single vs. multi-visit treatment. J Endodont 25:345-350

31. Trope M (1991) Flare up rate of single visit endodontics. Int Endodont J 24:24-26

32. Van Meerbeek, Vargas M, Inoue S, Yoshida $Y$, Peumans M, Lambrechts $P$, Vanherle G (2001) Adhesives and cements to promote preservation dentistry. Oper Dent 6:119-144

33. Weiger R, Rosendahl R, Lost C (2000) Influence of calcium hydroxide intracanal dressing on the prognosis of teeth with endodontically induced periapical lesions. Int Endod J 33:219-226

34. Wrong R (2004) Conventional endodontic failure and retreatment. Dent Clin North Am 48:265-289

35. Yoldas O, Topuz A, Isci AS, Oztunc H (2004) Postoperative pain after endodontic retreatment: Single vs. two visit treatment. Oral Surg Oral Med Oral Pathol Oral Radiol Endod 98:483-487 


\section{Captions for tables:}

\section{Tables}

Table 1. Distribution of prognostic factors, inception cohort, study sample and their association with healing and non-healing and $p$ values (Univariate analysis)

Table 2. Intra-examiner ( $T$ versus $K$ ) and inter-examiner Cohen`s Kappa values based on PAI scores that were recorded from the same radiographs within two months interval ( 1 versus 2 ) $\left({ }^{* *} p<0.01\right)$

Table 3. Distribution of investigated preoperative, intraoperative and postoperative variables and their significance in "healed" and "non-healed" groups ("Fisher's exact test; 'Fisher-Freeman Halton test; ${ }^{*} p<0.05$

Table 4. Effect of preoperative radiolucency and length of root filling on the outcomes of single appointment orthograde retreatment and odds ratio according to logistic regression model 
Tables:

\begin{tabular}{|c|c|c|c|c|c|}
\hline Prognostic factors & $\begin{array}{l}\text { Inception } \\
\text { Cohort } \\
\text { (n; \%) }\end{array}$ & $\begin{array}{l}\text { Study } \\
\text { sample } \\
(\mathrm{n} ; \%)\end{array}$ & $\begin{array}{l}\text { Non-healed } \\
(\mathrm{n} ; \%)\end{array}$ & $\begin{array}{l}\text { Healed } \\
(n ; \%)\end{array}$ & ${ }^{*} p$ \\
\hline \multicolumn{6}{|l|}{ Preoperative factors } \\
\hline \multicolumn{6}{|l|}{ Age } \\
\hline$\geq 45$ & $132(56.4)$ & $64(58.2)$ & $7(10.9)$ & $57(89.1)$ & \multirow{2}{*}{0.757} \\
\hline$<45$ & $102(43.6)$ & $46(41.8)$ & $3(6.5)$ & $43(93.5)$ & \\
\hline \multicolumn{6}{|l|}{ Gender } \\
\hline Male & $106(45.3)$ & $48(43.6)$ & $5(10.4)$ & $43(89.6)$ & \multirow{2}{*}{0.772} \\
\hline Female & $128(54.7)$ & $62(56.4)$ & $5(8.1)$ & 57 (91.9) & \\
\hline \multicolumn{6}{|l|}{ Preoperative pain } \\
\hline Present & $125(53.4)$ & $59(53.6)$ & $7(11.9)$ & $52(88.1)$ & \multirow{2}{*}{$0.97 C$} \\
\hline Absent & $109(46.6)$ & $51(46.4)$ & $3(5.9)$ & 48 (94.1) & \\
\hline \multicolumn{6}{|l|}{ Tooth } \\
\hline Maxillary anterior & $67(28.6)$ & $28(25.5)$ & $1(3.6)$ & $27(96.4)$ & \multirow{6}{*}{0.964} \\
\hline Mandibular anterior & $18(7.7)$ & $7(6.4)$ & $1(14.3)$ & $6(85.7)$ & \\
\hline Maxillary premolar & 46 (19.7) & $23(20.9)$ & $4(17.4)$ & $19(82.6)$ & \\
\hline Mandibular premolar & $38(16.2)$ & $20(18.2)$ & $1(5)$ & $19(95)$ & \\
\hline Maxillary molar & $27(11.5)$ & $15(13.6)$ & $1(6.7)$ & $14(93.3)$ & \\
\hline Mandibular molar & $38(16.2)$ & $17(15.5)$ & $2(11.8)$ & $15(88.2)$ & \\
\hline \multicolumn{6}{|l|}{ Radiolucency } \\
\hline Absent & $2(0.9)$ & $1(0.9)$ & $0(0)$ & $1(100)$ & \multirow{4}{*}{$0.21 \epsilon$} \\
\hline$<2 \mathrm{~mm}$ & $67(28.6)$ & $21(19.1)$ & $0(0)$ & $21(100)$ & \\
\hline $2-5 \mathrm{~mm}$ & $93(39.7)$ & $53(48.2)$ & $3(5.7)$ & $50(94.3)$ & \\
\hline$>5 \mathrm{~mm}$ & $72(30.8)$ & $35(31.8)$ & $7(20)$ & $28(80)$ & \\
\hline \multicolumn{6}{|c|}{ Preoperative PAl score } \\
\hline 1 & $0(0)$ & $0(0)$ & $0(0)$ & $0(0)$ & \multirow{5}{*}{0.43} \\
\hline 2 & $4(1.7)$ & $2(1.8)$ & $0(0)$ & $2(100)$ & \\
\hline 3 & $124(53)$ & $48(43.6)$ & $2(4.2)$ & $46(95.8)$ & \\
\hline 4 & $63(26.9)$ & $36(32.7)$ & $2(5.6)$ & $34(94.4)$ & \\
\hline 5 & $43(18.4)$ & $24(21.8)$ & $6(25)$ & $18(75)$ & \\
\hline \multicolumn{6}{|l|}{ Periodontal disease } \\
\hline Absent & $195(83.3)$ & $96(87.3)$ & $8(8.3)$ & $88(91.7)$ & \multirow[b]{2}{*}{0.345} \\
\hline Present & $39(16.7)$ & $14(12.7)$ & $2(14.3)$ & 12 (85.7) & \\
\hline \multicolumn{6}{|l|}{ Root filling density } \\
\hline Good & $6(2.6)$ & $2(1.8)$ & $0(0)$ & $2(100)$ & \multirow{3}{*}{0.408} \\
\hline Poor & $212(90.6)$ & $96(87.3)$ & $9(9.4)$ & $87(90.6)$ & \\
\hline Unfilled canal & $16(6.8)$ & $12(10.9)$ & $1(8.3)$ & $11(91.7)$ & \\
\hline \multicolumn{6}{|l|}{ Root-filling material } \\
\hline Gutta-percha & $220(94)$ & $100(90.9)$ & $9(9)$ & $91(91)$ & \multirow{3}{*}{0.448} \\
\hline Silver point & $0(0)$ & $0(0)$ & $0(0)$ & $0(0)$ & \\
\hline Paste & $16(6.8)$ & $10(9.1)$ & $2(20)$ & $8(80)$ & \\
\hline \multicolumn{6}{|l|}{ Length of root-filling } \\
\hline Adequate $(0-2 \mathrm{~mm})$ & $28(12)$ & $9(8.2)$ & $1(11.1)$ & $8(88.9)$ & \multirow{4}{*}{0.75} \\
\hline Short (>2 mm) & $195(83.3)$ & $95(86.4)$ & $7(7.4)^{\prime}$ & $88(92.6)$ & \\
\hline Beyond apex & $6(2.6)$ & $3(2.7)$ & $0(0)$ & $3(100)$ & \\
\hline Extensive overfill & $5(2.1)$ & $3(2.7)$ & $2(66.7)$ & 1 (33.3) & \\
\hline
\end{tabular}




\begin{tabular}{|c|c|c|c|c|c|}
\hline $\begin{array}{l}\text { Absent } \\
\text { Present }\end{array}$ & $\begin{array}{l}234(100) \\
0(0)\end{array}$ & $\begin{array}{l}110(100) \\
0(0)\end{array}$ & $\begin{array}{l}10(9.1) \\
0(0)\end{array}$ & $\begin{array}{l}100(90.9) \\
0(0)\end{array}$ & - \\
\hline \multicolumn{6}{|c|}{ Time since initial treatment } \\
\hline$\geq 1$ & $234(100)$ & $110(100)$ & $10(9.1)$ & $100(90.9)$ & \multirow{2}{*}{-} \\
\hline$<1$ & $0(0)$ & $0(0)$ & $0(0)$ & $0(0)$ & \\
\hline \multicolumn{6}{|c|}{ Previous apical surgery } \\
\hline No & $234(100)$ & $110(100)$ & $10(9.1)$ & $100(90.9)$ & \multirow[b]{2}{*}{-} \\
\hline Yes & $0(0)$ & $0(0)$ & $0(0)$ & $0(0)$ & \\
\hline \multicolumn{6}{|c|}{ Intraoperative factors } \\
\hline \multicolumn{6}{|c|}{ Root filling length } \\
\hline Adequate & 234 & 109 & 9 & 100 & \\
\hline Short & 0 & 1 & 1 & 0 & \\
\hline Long & 0 & 0 & 0 & 0 & \\
\hline \multicolumn{6}{|l|}{ Root filling voids } \\
\hline Absent & $234(100)$ & $110(100)$ & $10(9.1)$ & $100(90.9)$ & \multirow[b]{2}{*}{ - } \\
\hline Present & $0(0)$ & $0(0)$ & $0(0)$ & $0(0)$ & \\
\hline \multicolumn{6}{|l|}{ Complications } \\
\hline No & $234(100)$ & $110(100)$ & $10(9.1)$ & $100(90.9)$ & \multirow{2}{*}{-} \\
\hline Yes & $0(0)$ & $0(0)$ & $0(0)$ & $0(0)$ & \\
\hline \multicolumn{6}{|l|}{ Sealer extrusion } \\
\hline No & $152(65)$ & $60(54.5)$ & $4(6.7)$ & $56(93.3)$ & \multirow[b]{2}{*}{0.064} \\
\hline Yes & $82(35)$ & $50(45.5)$ & $6(12)$ & $44(88)$ & \\
\hline \multicolumn{6}{|c|}{ Temporary seal material } \\
\hline Temporary & $0(0)$ & $0(0)$ & $0(0)$ & $0(0)$ & \multirow[b]{2}{*}{ - } \\
\hline Definitive & $234(100)$ & $110(100)$ & $10(9.1)$ & $100(90.9)$ & \\
\hline \multicolumn{6}{|c|}{ Postoperative factors } \\
\hline \multicolumn{6}{|c|}{ Density of root-filling } \\
\hline Dense and tapered & & $110(100)$ & $10(9.1)$ & $100(90.9)$ & \\
\hline Voids present & & $0(0)$ & $0(0)$ & $0(0)$ & \\
\hline Poorly condensed & & $0(0)$ & $0(0)$ & $0(0)$ & \\
\hline \multicolumn{6}{|c|}{ Quality of coronal restoration } \\
\hline Adequate & & $108(98.2)$ & $10(9.3)$ & $98(90.7)$ & \\
\hline $\begin{array}{l}\text { Marginal deficiency } \\
\text { present }\end{array}$ & & $2(1.8)$ & $0(0)$ & $2(100)$ & \\
\hline \multicolumn{6}{|c|}{ Postoperative signs and symptoms } \\
\hline Absent & & $109(99.1)$ & $9(8.3)$ & $100(91.7)$ & \\
\hline Present & & $1(0.9)$ & $1(100)$ & $0(0)$ & \\
\hline \multicolumn{6}{|l|}{ Radiolucency } \\
\hline Absent & & $101(91.8)$ & $1(1)$ & $100(99)$ & \\
\hline Present & & $9(8.2)$ & $9(100)$ & $0(0)$ & \\
\hline \multicolumn{6}{|c|}{ Postoperative PAI score } \\
\hline 1 & & $75(68.2)$ & $0(0)$ & $75(100)$ & \\
\hline 2 & & $25(22.7)$ & $0(0)$ & $25(100)$ & \\
\hline$\overline{3}$ & & $5(4.5)$ & $5(100)$ & $0(0)$ & \\
\hline 4 & & $4(3.6)$ & $4(100)$ & $0(0)$ & \\
\hline 5 & & $1(0.9)$ & $1(100)$ & $0(0)$ & \\
\hline \multicolumn{6}{|l|}{ Fracture } \\
\hline Absent & & $110(100)$ & $10(9.1)$ & $100(90.9)$ & \\
\hline Present & & $0(0)$ & $0(0)$ & $0(0)$ & \\
\hline
\end{tabular}




\begin{tabular}{|c|c|c|c|c|c|}
\hline $\begin{array}{l}\text { Definitive filling } \\
\text { Crown }\end{array}$ & & $\begin{array}{l}36(32.7) \\
75(68.2)\end{array}$ & $\begin{array}{l}3(8.3) \\
7(9.3) \\
\end{array}$ & $\begin{array}{l}33(91.7) \\
68(90.7) \\
\end{array}$ & \\
\hline Post & & & & & \\
\hline $\begin{array}{l}\text { Absent } \\
\text { Present }\end{array}$ & $\begin{array}{l}165(70.5) \\
69(29.5)\end{array}$ & $\begin{array}{l}76(69.1) \\
34(30.9)\end{array}$ & $\begin{array}{l}8(10.5) \\
2(5.9)\end{array}$ & $\begin{array}{l}68(89.5) \\
32(94.1)\end{array}$ & 0.788 \\
\hline
\end{tabular}

Table 1. Distribution of prognostic factors, inception cohort, study sample and their association with healing and nonhealing and $p$ values (Univariate analysis)

\begin{tabular}{ccccc}
\hline \multirow{2}{*}{ PAI } & \multicolumn{2}{c}{ Intra-examiner } & \multicolumn{2}{c}{ Inter-examiner } \\
\cline { 2 - 5 } & $\mathrm{T} 1-\mathrm{T} 2$ & $\mathrm{~K} 1-\mathrm{K} 2$ & $\mathrm{~T} 1-\mathrm{K} 1$ & $\mathrm{~T} 2-\mathrm{K} 2$ \\
\cline { 2 - 5 } & $\mathrm{n}(\%)$ & $\mathrm{n}(\%)$ & $32(23)$ & $\mathrm{n}(\%)$ \\
\hline \hline $\mathbf{1}$ & $33(23.7)$ & $31(22.3)$ & $34(24.5)$ & $29(20.9)$ \\
$\mathbf{2}$ & $35(25.2)$ & $35(25.2)$ & $25(18)$ & $37(26.6)$ \\
$\mathbf{3}$ & $23(16.5)$ & $25(18)$ & $29(20.9)$ & $30(17.3)$ \\
$\mathbf{4}$ & $29(20.9)$ & $29(20.9)$ & $19(13.7)$ & $19(13.7)$ \\
$\mathbf{5}$ & $19(13.7)$ & $19(13.7)$ & 0.964 & 0.964 \\
\hline Cohen's Kappa & 0.936 & 0.955 & $($ very good) & (very good) \\
& (very good) & (very good) & $<0.001^{* *}$ & $<0.001^{* *}$ \\
\hline
\end{tabular}

Table 2. Intra-examiner ( $T$ versus $K$ ) and inter-examiner Cohen's Kappa values based on PAl scores that were recorded from the same radiographs within two months interval (1 versus 2$)\left({ }^{* *} p<0.01\right)$ 


\begin{tabular}{|c|c|c|c|c|c|c|}
\hline & & $\mathbf{n}$ & $\begin{array}{c}\text { Healed } \\
(n=100) \\
(n ; \%)\end{array}$ & $\begin{array}{l}\text { Non-healed } \\
(n=10)\end{array}$ & $\mathbf{p}$ & $\begin{array}{c}\text { Post-hoc } \\
\text { power }\end{array}$ \\
\hline \multicolumn{7}{|l|}{ Preoperative factors } \\
\hline Preoperative pain & $\begin{array}{l}\text { Absent } \\
\text { Present }\end{array}$ & $\begin{array}{l}51 \\
59\end{array}$ & $\begin{array}{l}48(94.1) \\
52(88.1)\end{array}$ & $\begin{array}{l}3(5.9) \\
7(11.9)\end{array}$ & ${ }^{\mathrm{a}} 0.334$ & 0.304 \\
\hline $\begin{array}{l}\text { Preoperative } \\
\text { radiolucency }\end{array}$ & $\begin{array}{l}<2 \mathrm{~mm} \\
2-5 \mathrm{~mm} \\
>5 \mathrm{~mm}\end{array}$ & $\begin{array}{l}21 \\
54 \\
35\end{array}$ & $\begin{array}{l}21(100) \\
51(94.4) \\
28(80)\end{array}$ & $\begin{array}{l}0 \\
3(5.6) \\
7(20)\end{array}$ & ${ }^{\mathrm{b}} 0.025^{*}$ & 0.715 \\
\hline $\begin{array}{l}\text { Preoperative PAI } \\
\text { scores }\end{array}$ & $\begin{array}{l}3 \\
4 \\
5\end{array}$ & $\begin{array}{l}50 \\
36 \\
24\end{array}$ & $\begin{array}{l}48(96) \\
34(94.4) \\
18(75)\end{array}$ & $\begin{array}{l}2(4) \\
2(5.6) \\
6(25)\end{array}$ & ${ }^{\mathrm{b}} 0.014^{*}$ & 0.792 \\
\hline & $\begin{array}{l}\text { Min-max (median) } \\
\text { Mean } \pm S D\end{array}$ & & $\begin{array}{l}3-5(4) \\
3.7 \pm 0.76\end{array}$ & $\begin{array}{l}3-5(5) \\
4.4 \pm 0.84\end{array}$ & & \\
\hline Peridontal defects & $\begin{array}{l}\text { Absent } \\
\text { Present }\end{array}$ & $\begin{array}{l}96 \\
14\end{array}$ & $\begin{array}{l}88(91.7) \\
12(85.7)\end{array}$ & $\begin{array}{l}8(8.3) \\
2(14.3)\end{array}$ & ${ }^{\mathrm{a}} 0.613$ & 0.142 \\
\hline Root filling density & $\begin{array}{l}\text { Good } \\
\text { Poor } \\
\text { Unfilled }\end{array}$ & $\begin{array}{l}2 \\
96 \\
12\end{array}$ & $\begin{array}{l}2(100) \\
87(90.6) \\
11(91.7)\end{array}$ & $\begin{array}{l}0 \\
9(9.4) \\
1(8.3)\end{array}$ & ${ }^{b} 1.000$ & 0.067 \\
\hline Length of root-fill & $\begin{array}{l}\text { Adeguate } \\
\text { Short }(>2 \mathrm{~mm}) \\
\text { Beyond apex } \\
\text { Extensive overfill }\end{array}$ & $\begin{array}{l}11 \\
95 \\
3 \\
1\end{array}$ & $\begin{array}{l}9(81.8) \\
88(92.6) \\
3(100) \\
0\end{array}$ & $\begin{array}{l}2(18.2) \\
7(7.4) \\
0 \\
1(100)\end{array}$ & ${ }^{\mathrm{b}} 0.072$ & 0.831 \\
\hline \multicolumn{7}{|l|}{ Intraoperative factors } \\
\hline Sealer extrusion & $\begin{array}{l}\text { Yes } \\
\text { No }\end{array}$ & $\begin{array}{l}50 \\
60\end{array}$ & $\begin{array}{l}44(88) \\
56(93.3)\end{array}$ & $\begin{array}{l}6(12) \\
4(6.7)\end{array}$ & ${ }^{a} 1.000$ & 0.157 \\
\hline \multicolumn{7}{|l|}{ Postoperative factors } \\
\hline $\begin{array}{l}\text { Restoration at follow- } \\
\text { up }\end{array}$ & $\begin{array}{l}\text { Definitive } \\
\text { Crown }\end{array}$ & $\begin{array}{l}36 \\
74\end{array}$ & $\begin{array}{l}33(91.7) \\
67(90.5)\end{array}$ & $\begin{array}{l}3(8.3) \\
7(9.5)\end{array}$ & ${ }^{a} 1.000$ & 0.042 \\
\hline Post & $\begin{array}{l}\text { Absent } \\
\text { Present }\end{array}$ & $\begin{array}{l}76 \\
34\end{array}$ & $\begin{array}{l}68(89.5) \\
32(94.1)\end{array}$ & $\begin{array}{l}8(10.5) \\
2(5.9)\end{array}$ & ${ }^{\mathrm{a}} 0.721$ & 0.089 \\
\hline
\end{tabular}

Table 3. Distribution of investigated preoperative, intraoperative and postoperative variables and their significance in "healed" and "non-healed" groups ( ${ }^{a} F i s h e r ' s ~ e x a c t ~ t e s t ; ~ '{ }^{b} F i s h e r-F r e e m a n$ Halton test; * $p<0.05$ ) 


\begin{tabular}{|c|c|c|c|c|}
\hline & \multirow[t]{2}{*}{$\mathbf{p}$} & \multirow[t]{2}{*}{ Odds ratio } & \multicolumn{2}{|l|}{$\% 95 \mathrm{Cl}$} \\
\hline & & & Lower & Upper \\
\hline Preopoperative & $0.012^{*}$ & 6.415 & 1.509 & 27.266 \\
\hline \multicolumn{5}{|l|}{ radiolucency (>5 $\mathrm{mm}$ ) } \\
\hline Length of root-filling (Adequate) & 0.220 & 3.129 & 0.506 & 19.354 \\
\hline
\end{tabular}

Table 4. Effect of preoperative radiolucency and length of root filling on the outcomes of single appointment orthograde retreatment and odds ratio according to logistic regression model 